\title{
Maltose-Functionalized Hydrophilic Magnetic Nanoparticles with Polymer Brushes for Highly Selective Enrichment of N-Linked Glycopeptides
}

\author{
Changfen Bi, ${ }^{\dagger}$ Yulu Liang, ${ }^{\ddagger} \S$ Lijin Shen, "Shanshan Tian, "Kai Zhang, $"$ Yiliang Li, ${ }^{\dagger}$ Xiwen He, \\ Langxing Chen, $*,+, \S_{\odot}$ and Yukui Zhang ${ }^{\ddagger, \perp}$
}

${ }^{\dagger}$ Tianjin Key Laboratory of Radiation Medicine and Molecular Nuclear Medicine, Institute of Radiation Medicine, Peking Union Medical College \& Chinese Academy of Medical Sciences, Tianjin 300192, China

${ }^{\ddagger}$ Research Center for Analytical Sciences, College of Chemistry, Tianjin Key Laboratory of Biosensing and Molecular Recognition, State Key Laboratory of Medicinal Chemical Biology, Nankai University, Tianjin 300071, China

${ }^{\S}$ Collaborative Innovation Center of Chemical Science and Engineering (Tianjin), Tianjin 300071, China

"2011 Collaborative Innovation Center of Tianjin for Medical Epigenetics, Tianjin Medical University, Tianjin 300070, China

${ }^{\perp}$ Dalian Institute of Chemical Physics, Chinese Academy of Sciences, Dalian 116023, China

Supporting Information

\begin{abstract}
Efficient enrichment glycoproteins/glycopeptides from complex biological solutions are very important in the biomedical sciences, in particular biomarker research. In this work, the high hydrophilic polyethylenimine conjugated polymaltose polymer brushes functionalized magnetic $\mathrm{Fe}_{3} \mathrm{O}_{4}$ nanoparticles (NPs) denoted as $\mathrm{Fe}_{3} \mathrm{O}_{4}-\mathrm{PEI}-\mathrm{pMaltose}$ were designed and synthesized via a simple two-step modification. The obtained superhydrophilic $\mathrm{Fe}_{3} \mathrm{O}_{4}-\mathrm{PEI}-\mathrm{pMaltose} \mathrm{NPs}$ displayed outstanding advantages in the enrichment of N-linked glycopeptides, including high selectivity (1:100, mass ratios of HRP and bovine serum albumin (BSA) digest), low detection limit (10 fmol), large binding capacity (200 mg/g), and high enrichment recovery (above $85 \%$ ). The above-mentioned excellent performance of novel $\mathrm{Fe}_{3} \mathrm{O}_{4}-\mathrm{PEI}-\mathrm{pMaltose}$ NPs was attributed to graft of maltose polymer brushes and efficient assembly strategy. Moreover, $\mathrm{Fe}_{3} \mathrm{O}_{4}-\mathrm{PEI}-\mathrm{pMaltose}$ NPs were further utilized to selectively enrich glycopeptides from human renal mesangial cell (HRMC, $200 \mu \mathrm{g}$ ) tryptic digest, and $449 \mathrm{~N}$ linked glycopeptides, representing 323 different glycoproteins and 476 glycosylation sites, were identified. It was expected that the as-synthesized $\mathrm{Fe}_{3} \mathrm{O}_{4}-\mathrm{PEI}-$ pMaltose NPs, possessing excellent performance (high binding capacity, good selectivity, low detection limit, high enrichment recovery, and easy magnetic separation) coupled to a facile preparation procedure, have a huge potential in $\mathrm{N}$-glycosylation proteome analysis of complex biological samples.
\end{abstract}

\section{INTRODUCTION}

Protein N-glycosylation, as one of the most common and significant post-translational modifications, plays an important role in biological processes, such as cell signal transduction, protein folding, cell recognition, etc. ${ }^{1-3}$ Aberrant protein Nglycosylation is frequently involved in many major human diseases, including cancer, Alzheimer's disease (AD), and infectious disease. ${ }^{4,5}$ Therefore, the efficient isolation and identification of $\mathrm{N}$-glycopeptides is especially beneficial for understating their biological functions and for the discovery of new clinical biomarkers and therapeutic drug targets. Currently, mass spectrometry (MS) is a powerful and effective tool in proteomics which provides the possibility to analyze the $\mathrm{N}$ glycoproteome. ${ }^{6-8}$ However, owing to the matrix complexity of biological samples, a low abundance of glycoproteins, and severe ion signal suppression of nonglycopeptides, it remains still an analytical challenge to comprehensively characterize glycoproteins. Therefore, an effective enrichment of glycopepetides prior to MS analysis becomes imperative to elucidate the structures of glycans and clarify glycan-attached sites.

The common enrichment strategies based on glycan-specific recognition or glycan physicochemical properties for glycosy- lated proteins/peptides, including lectin affinity, ${ }^{9-12}$ hydrazide chemistry, ${ }^{13-15}$ boronic acid chemistry, ${ }^{16-21}$ and hydrophilic interaction liquid chromatography (HILIC), ${ }^{22-25}$ have been developed. Among them, HILIC has aroused much attention for glycopeptides enrichment by utilizing the strong hydrophilicity of the glycopeptides and HILIC materials, due to its broad glycan specificity, excellent reproducibility, and good MS compatibility. ${ }^{26,27}$ Until now, a number of HILIC nanomaterials have been synthesized by introducing hydrophilic functional groups onto the surface of mesoporous silica, graphene oxide, metal-organic frameworks, and magnetic nanoparticles. ${ }^{28-35}$ In virtue of their strong magnetic responsibility, good biocompatibility, easy and versatile modification, $\mathrm{Fe}_{3} \mathrm{O}_{4}$ nanoparticles (NPs) based on magnetic separation has become an effective isolation technique in proteomic research. ${ }^{36-38}$ The hydrophilic ligands, immobilized on magnetic nanoparticles, would simultaneously achieve fast separation and low loss of $\mathrm{N}$ linked glycopeptides from a complex sample under an external

Received: November 14, 2017

Accepted: January 24, 2018

Published: February 7, 2018 
Scheme 1. Schematic Illustration of the Fabrication of $\mathrm{Fe}_{3} \mathrm{O}_{4}-\mathrm{PEI}-\mathrm{pMaltose} \mathrm{NPs}$ and the Selective Enrichment Process for the N-Linked Glycopeptides

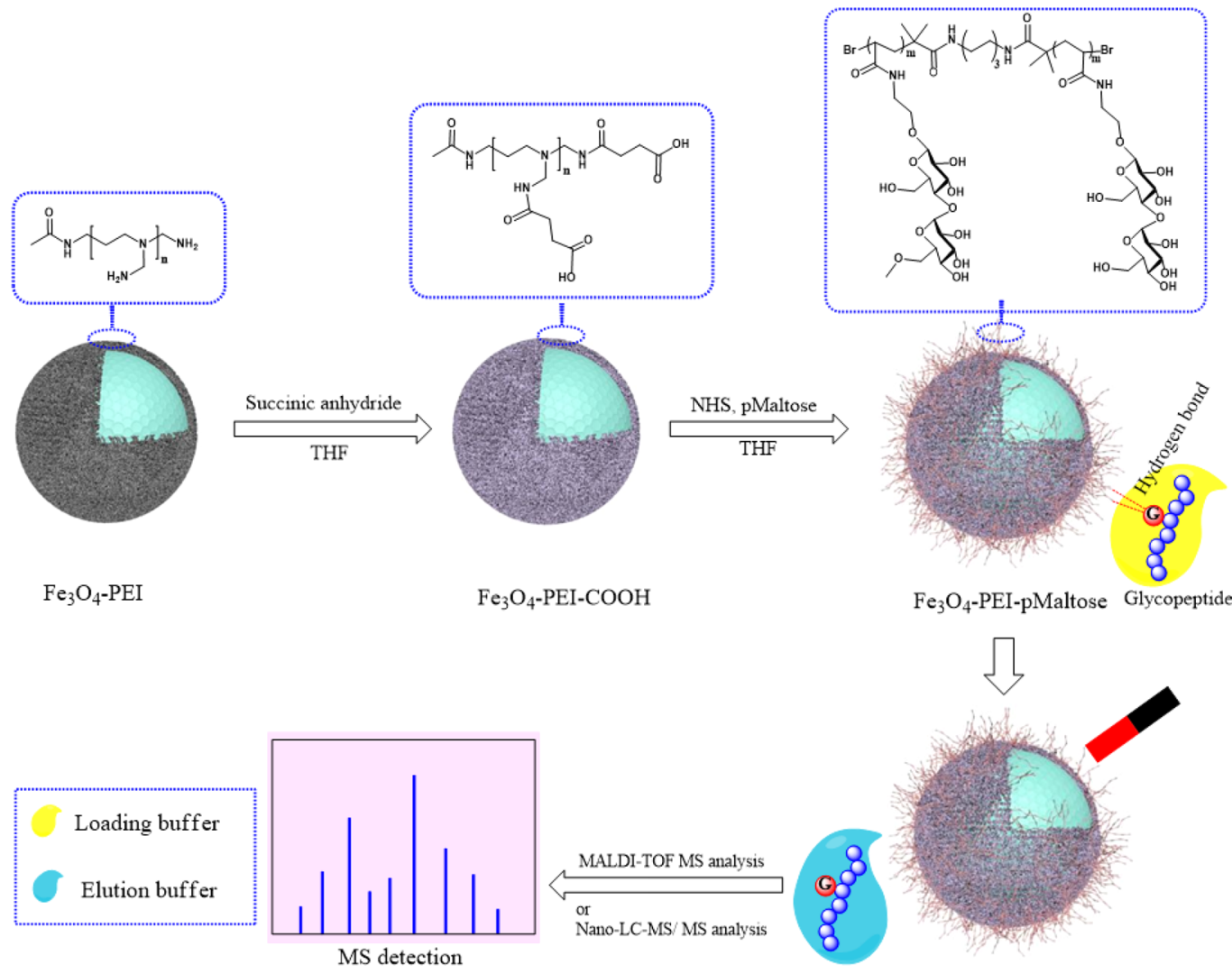

magnetic field. However, most of HILIC adsorbents need tedious synthesis steps and harsh conditions to acquire the functional moieties; this leads to relative low binding capacity and enrichment selectivity. It has been reported that more hydrophilic functional groups grafted on the surface of HILIC substrates lead to a better performance of glycopeptides from the highly complex biosamples. ${ }^{23}$ Therefore, there is great demand to obtain ultrahydrophilic nanocomposites with more functional groups by a facile synthesis procedure for specific enrichment, especially for $\mathrm{N}$-linked glycopeptide enrichment in complex samples.

Herein, a new type of maltose-functionalized hydrophilic magnetic nanoparticles, $\mathrm{Fe}_{3} \mathrm{O}_{4}$-polyethylenimine-polymaltose denoted as $\mathrm{Fe}_{3} \mathrm{O}_{4}-\mathrm{PEI}-$ pMaltose, was assembled by a facile strategy (Scheme 1). Briefly, PEI-coated magnetic $\mathrm{Fe}_{3} \mathrm{O}_{4} \mathrm{NPs}$ were prepared by solvothermal reaction, then succinic anhydride was reacted with the surface amino groups of PEI. Maltose polymer brushes (Scheme S1, Supporting Information) were grafted on the surface of magnetic $\mathrm{Fe}_{3} \mathrm{O}_{4}$ NPs via an esterification reaction. The abundant maltose on the surface of $\mathrm{Fe}_{3} \mathrm{O}_{4}$ NPs could specifically enrich glycopeptides, and the magnetic core makes the NPs separate easily from solution under an external magnetic field. In addition, the hydrophilic polymer can provide low adsorption of nonglycopeptides, which ensures the novel nanocomposite with high selectivity, sensitivity, large binding capacity, and high recovery for Nglycopeptides enrichment.

\section{EXPERIMENTAL SECTION}

Materials. Horseradish peroxidase (HRP), immunoglobulin G (IgG), peptide- $N 4$ - $(N$-acetyl- $\beta$-D-glucosaminyl) asparagine amidase F (PNGase F) and bovine serum albumin (BSA) were obtained from Sigma-Aldrich, USA. Polyethylenemine (PEI, $\left.M_{\mathrm{w}}=70000\right)$ was obtained from Alfa Aesar, Tianjin, China. Dithiothreitol (DTT), urea, ammonium bicarbonate $\left(\mathrm{NH}_{4} \mathrm{HCO}_{3}\right)$, and iodoacetamide (IAA) were purchased from Solarbio, China. Trifluoroacetic acid (TFA), Amberlite IR 120 and 2-bromoethanol were purchased from J\&K, China. $N, N, N^{\prime}, N^{\prime \prime}, N^{\prime \prime}$-Pentamethyldiethylenetriamine (PMDETA) and 2-bromo-2-methylpropionyl bromide were from Aladdin, China. 2,5-Dihydroxybenzoic acid (DHB) was purchased from TCI, Japan. Trypsin was from Sangon Biotech Co. Led., China. Dicyclohexylcarbodiimide (DCC) and $N$-hydroxysuccinimide (NHS) were obtained from Shanghai Medpep. Co., China. Iron(III) chloride hexahydrate $\left(\mathrm{FeCl}_{3} \cdot 6 \mathrm{H}_{2} \mathrm{O}\right)$, sodium sulfate $\left(\mathrm{Na}_{2} \mathrm{SO}_{4}\right)$, succinic anhydride, tetrahydrofuran (THF), triethylamine $\left(\mathrm{Et}_{3} \mathrm{~N}\right)$, dimethyl sulfoxide (DMSO), D-(+)-maltose and other analytical grade reagents were obtained from Tianjin Chemical Reagent Factory, China. Deionized water (18.25 M $\Omega$ $\mathrm{cm}$ ) was purified with a Milli-Q water system, Millipore, Milford, MA, USA.

Characterization. Transmission electron microscope (TEM) characterization was carried out on a JEOL JEM2100 EX transmission electron microscope (Japan). Scanning electron microscope (SEM) measurement was performed on a JSM-6360LV scanning electron microscope (Japan). Hydrodynamic diameter $\left(D_{\mathrm{h}}\right)$ measurement was performed with a Brookhaven BI-200SM instrument (USA). Fourier transform infrared (FT-IR) spectra in $\mathrm{KBr}$ were recorded using the BRUKER TENSOR 27 Fourier transform infrared spectrophotometer. The crystal structure of nanoparticles was determined on a Rigaku $\mathrm{D} / \mathrm{max} / 2500 \mathrm{v} / \mathrm{pc}$, Japan. The X-ray diffraction 

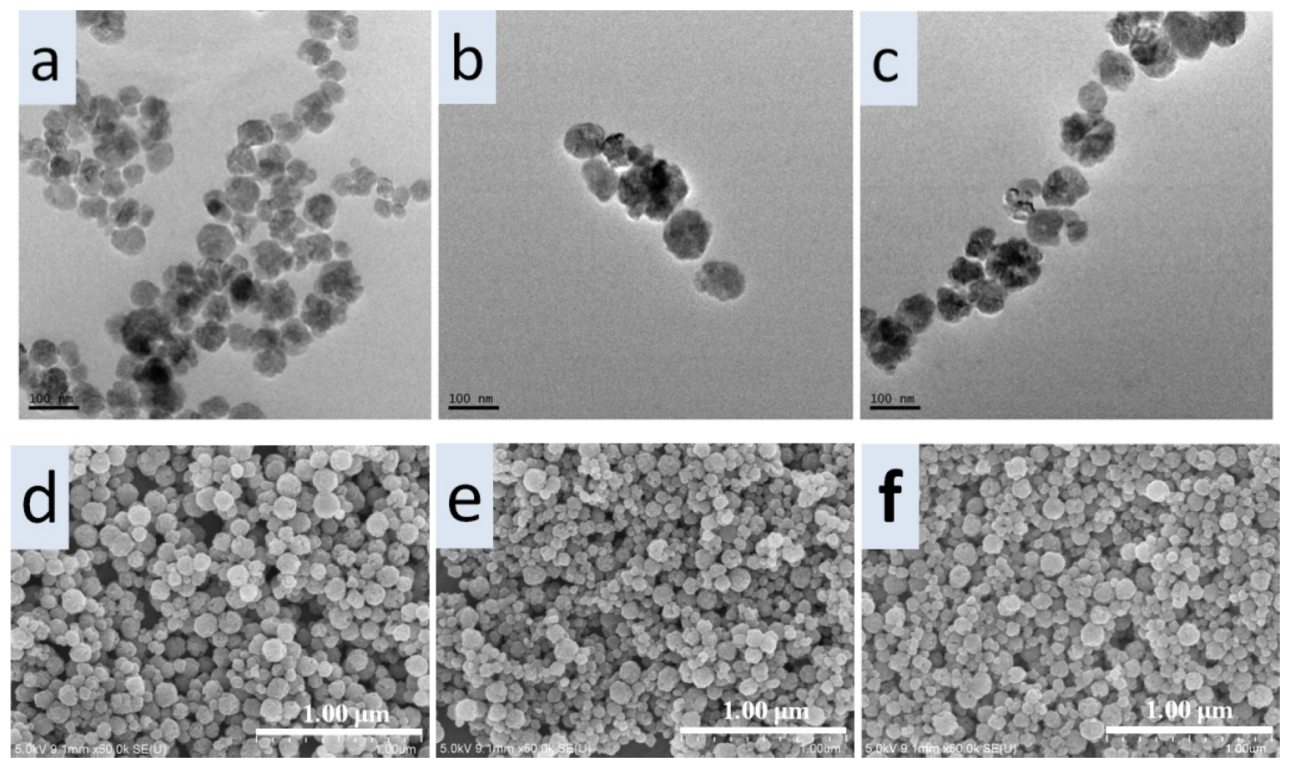

Figure 1. TEM imagesof $\mathrm{Fe}_{3} \mathrm{O}_{4}-\mathrm{PEI}(\mathrm{a}), \mathrm{Fe}_{3} \mathrm{O}_{4}-\mathrm{PEI}-\mathrm{COOH}$ (b), $\mathrm{Fe}_{3} \mathrm{O}_{4}-\mathrm{PEI}-\mathrm{pMaltose}(\mathrm{c}), \mathrm{NPs}$ and SEM image of Fe $\mathrm{O}_{4}-\mathrm{PEI}(\mathrm{d})$, $\mathrm{Fe} \mathrm{O}_{3}-$ PEI-COOH (e), $\mathrm{Fe}_{3} \mathrm{O}_{4}-\mathrm{PEI}-$ pMaltose (f) NPs, respectively.

(XRD) pattern was carried out on a Rigaku D/max/2500 X-ray diffractometer, Japan. The X-ray photoelectron spectra (XPS) was obtained on a Shimadzu Kratos AXIS Ultra DLD X-ray photoelectron spectrometer, Japan. The magnetic properties were analyzed with a LDJ9600-1 vibrating sample magnetometer, USA. The hydrophilicity was evaluated with JCY-1 contact angle analyzer, China. Zeta potential was measured by a Brookhaven ZetaPALS potentiometric analyzer, USA.

MALDI-TOF MS measurements were performed on a Bruker AutoflexIII LRF200-CID instrument, Germany. DHB $\left(25 \mathrm{mg} / \mathrm{mL}, V(\mathrm{ACN}) / V\left(\mathrm{H}_{2} \mathrm{O}\right) / V(\mathrm{TFA})=80: 19: 1\right)$ was used as matrix. All the LC-MS/MS analyses were carried out on a Orbitrap Q-Exactive mass spectrometer, Thermo Fisher Scientific, Waltham, MA.

Preparation of $\mathrm{Fe}_{3} \mathrm{O}_{4}-$ PEI NPs. $\mathrm{Fe}_{3} \mathrm{O}_{4}-$ PEI NPs were synthesized by the solvothermal method. ${ }^{34}$ Typically, $1.8 \mathrm{~g}$ of $\mathrm{FeCl}_{3} \cdot 6 \mathrm{H}_{2} \mathrm{O}, 7.2 \mathrm{~g}$ of $\mathrm{NaAc}$, and $1.8 \mathrm{~g}$ of PEI were dissolved in $90 \mathrm{~mL}$ of EG under sonication to give a homogeneous solution which was then stirred mechanically for $30 \mathrm{~min}$ at $60{ }^{\circ} \mathrm{C}$. Then the resulting solution was poured into a autoclave and reacted at $220{ }^{\circ} \mathrm{C}$ for $2 \mathrm{~h}$. Deionized water alternates with ethanol three times to wash the $\mathrm{Fe}_{3} \mathrm{O}_{4}-\mathrm{PEI}$ NPs. Finally, the resulting $\mathrm{Fe}_{3} \mathrm{O}_{4}-$ PEI NPs were dried in vacuum oven.

Preparation of $\mathrm{Fe}_{3} \mathrm{O}_{4}-\mathrm{PEI}-\mathrm{COOH}$ NPs. The succinic anhydride $\left(2.5 \mathrm{~g}\right.$ ) was added into the solution of $\mathrm{Fe}_{3} \mathrm{O}_{4}$-PEI NPs $(500 \mathrm{mg})$ in dry THF $(120 \mathrm{~mL})$. The dispersion solution was refluxed for $12 \mathrm{~h}$. The obtained $\mathrm{Fe}_{3} \mathrm{O}_{4}-\mathrm{PEI}-\mathrm{COOH} \mathrm{NPs}$ were washed several times using deionized water and ethanol and dried in vacuum oven.

Synthesis of $\mathrm{Fe}_{3} \mathrm{O}_{4}-\mathrm{PEI}-\mathrm{pMaltose} \mathrm{NPs}$. The succinic anhydride $(500 \mathrm{mg})$ was added into the THF solution $(22 \mathrm{~mL})$ containing $\mathrm{Fe}_{3} \mathrm{O}_{4}-\mathrm{PEI}-\mathrm{COOH}$ NPs $(100 \mathrm{mg})$. After ultrasonic dispersion uniformity, the solution was reacted at $60{ }^{\circ} \mathrm{C}$ for $12 \mathrm{~h}$. The activated $\mathrm{Fe}_{3} \mathrm{O}_{4}-\mathrm{PEI}-\mathrm{COOH}$ NPs were washed with dry THF and were dispersed in dry THF $(120 \mathrm{~mL})$ containing maltose polymer (Supporting Information, $200 \mathrm{mg}$ ) and $\mathrm{Et}_{3} \mathrm{~N}(800 \mu \mathrm{L})$. After reaction at $60^{\circ} \mathrm{C}$ for $4 \mathrm{~h}$, the $\mathrm{Fe}_{3} \mathrm{O}_{4}-$ PEI-pMaltose NPs were obtained.
Digestion of Proteins. Standard proteins (HRP, IgG, and BSA) were digested according to the previous literature. ${ }^{33}$ Briefly, the proteins were dissolved in $50 \mathrm{mM}$ of $\mathrm{NH}_{4} \mathrm{HCO}_{3}$ solution and denatured by boiling or $8 \mathrm{M}$ urea. The denatured proteins were reduced with DTT and alkylated by IAA in sequence. After emzymolysis with trypsin, the peptide solution was frozen at $-20{ }^{\circ} \mathrm{C}$ for standby application.

One $\mathrm{mg}$ protein extraction from human renal mesangial cells (HRMC) was precipitated by TCA. The pellet was resuspended in $100 \mathrm{mM}$ of $\mathrm{NH}_{4} \mathrm{HCO}_{3}$. The proteins underwent reduction, alkylation, and emzymolysis in sequence. The resulting digests were desalted and enriched using Sep-pak C18 cartridges (Waters Ltd., Elstree, UK), evaporated to dryness.

Isotope Dimethylation Labeling of Human IgG Tryptic Digest. Stable isotope dimethyl labeling was performed as the following procedures: After the C18 StageTip desalting step, tryptic peptides of IgG $(100 \mu \mathrm{g})$ were dissolved in sodium acetate buffer $(100 \mu \mathrm{L}, 100 \mathrm{mM}, \mathrm{pH} 5-6)$, and then transferred in equal amount into two tubes. The solutions (50 $\mu \mathrm{L})$ were mixed with $8 \mu \mathrm{L}$ of $\mathrm{CH}_{2} \mathrm{O}(4 \%, \mathrm{v} / \mathrm{v})$ or $8 \mu \mathrm{L}$ of $\mathrm{CD}_{2} \mathrm{O}(4 \%, \mathrm{v} / \mathrm{v})$, which were labeled as light (L) and heavy $(\mathrm{H})$, separately. After a brief vortexing, $8 \mu \mathrm{L}$ of $\mathrm{NaBH}_{3} \mathrm{CN}$ solution $(0.6 \mathrm{M})$ in water was added to the $\mathrm{L}$ and $\mathrm{H}$ labeled samples, respectively. The reactions were terminated with $8 \mu \mathrm{L}$ of $4 \%$ ammonia solution after shaking for $1 \mathrm{~h}$.

Glycopeptides Enrichment under Hydrophilic Mode. $\mathrm{Fe}_{3} \mathrm{O}_{4}-\mathrm{PEI}-\mathrm{pMaltose} \mathrm{NPs}$ (or $\mathrm{Fe}_{3} \mathrm{O}_{4}-\mathrm{PEI}, \mathrm{Fe}_{3} \mathrm{O}_{4}-\mathrm{PEI}-$ $\mathrm{COOH}$ NPs, $15 \mu \mathrm{g}$ ) was washed thrice with loading buffer $\left(V(\mathrm{ACN}) / V\left(\mathrm{H}_{2} \mathrm{O}\right) / V(\mathrm{TFA})=92: 7.9: 0.1\right)$ and dispersed in the above buffer $(400 \mu \mathrm{L})$ containing a determined amount of standard protein digests. After being incubated for $30 \mathrm{~min}$, the NPs were washed thrice with the $400 \mu \mathrm{L}$ loading buffer. Finally, the $\mathrm{N}$-glycopeptides captured by $\mathrm{Fe}_{3} \mathrm{O}_{4}-\mathrm{PEI}-\mathrm{pMaltose} \mathrm{NPs}$ were released by elution buffer $\left(2 \times 13 \mu \mathrm{L}, V(\mathrm{ACN}) / V\left(\mathrm{H}_{2} \mathrm{O}\right) /\right.$ $V($ TFA $)=30: 69.9: 0.1)$ for $6 \mathrm{~min}$. The supernatant was collected, lyophilized, redissolved in $4 \mu \mathrm{L}$ of elution buffer and analyzed by MALDI-TOF MS. 
For the glycopeptide enrichment from human renal mesangial cells, $200 \mu \mathrm{g}$ of the digests was dissolved in $6 \mathrm{~mL}$ loading buffer $\left(80 \% \mathrm{ACN} / \mathrm{H}_{2} \mathrm{O}, 0.1 \% \mathrm{FA}\right)$, incubated with 20 mg of $\mathrm{Fe}_{3} \mathrm{O}_{4}-\mathrm{PEI}-\mathrm{pMaltose} \mathrm{NPs}$ for $1 \mathrm{~h}$, and subsequently washed thrice with $2 \mathrm{~mL}$ of loading buffer. Then, the trapped glycopeptides were eluted twice with $400 \mu \mathrm{L}$ of elution buffer for $30 \mathrm{~min}$, and the elution was evaporated to dryness. The obtained glycopeptides were redissolved in $10 \mathrm{mM} \mathrm{NH}_{4} \mathrm{HCO}_{3}$, and glycan moieties were removed by 1000 units of PNGase F. The mixture was desalted and enriched using Sep-pak C18 cartridges (Waters Ltd., Elstree, UK), evaporated to dryness, and redissolved prior to analysis by nano LC-MS/MS.

\section{RESULTS AND DISCUSSION}

Preparation and Characterization of $\mathrm{Fe}_{3} \mathrm{O}_{4}-\mathrm{PEI}-$ pMaltose NPs. The size and morphology of obtained $\mathrm{Fe}_{3} \mathrm{O}_{4}-\mathrm{PEI}, \mathrm{Fe}_{3} \mathrm{O}_{4}-\mathrm{PEI}-\mathrm{COOH}$ and $\mathrm{Fe}_{3} \mathrm{O}_{4}-\mathrm{PEI}-$ pMaltose NPs were characterized by TEM and SEM. As shown in Figure 1 , after the modification of short chain carboxylic acid and maltose polymer brush on the layer of $\mathrm{Fe}_{3} \mathrm{O}_{4}$-PEI NPs with covalent bond, the corresponding NPs still exhibited good dispersity and almost no changes in particle sizes. Also, from the TEM image, the diameter of the resulting $\mathrm{Fe}_{3} \mathrm{O}_{4}-\mathrm{PEI}-$ pMaltose NPs was about $60-100 \mathrm{~nm}$, which is consistent with the hydrodynamic diameter by dynamic light scattering technique (Figure S1). Because the maltose polymer was prepared by atom transfer radical polymerization (ATRP) in the presence of a mole ratio of 20:1 for maltose monomer and initiator bis(2-bromoisobutyryl) hexanediamide (Supporting Information), the polymer lines of pMaltose are short, which did not result in great size change of $\mathrm{Fe}_{3} \mathrm{O}_{4}-\mathrm{PEI}-\mathrm{pMaltose}$ NPs after immobilization on the surface of magnetic $\mathrm{Fe}_{3} \mathrm{O}_{4}-$ PEI NPs.

The zeta potentials of $\mathrm{Fe}_{3} \mathrm{O}_{4}-\mathrm{PEI}, \mathrm{Fe}_{3} \mathrm{O}_{4}-\mathrm{PEI}-\mathrm{COOH}$ and $\mathrm{Fe}_{3} \mathrm{O}_{4}$-PEI-pMaltose NPs were monitored to further demonstrate successful modification of $\mathrm{Fe}_{3} \mathrm{O}_{4} \mathrm{NPs}$. The zeta potentials of $\mathrm{Fe}_{3} \mathrm{O}_{4}-\mathrm{PEI}, \mathrm{Fe}_{3} \mathrm{O}_{4}-\mathrm{PEI}-\mathrm{COOH}$ and $\mathrm{Fe}_{3} \mathrm{O}_{4}-$ PEI-pMaltose NPs were $-25.54 \pm 1.23,-33.51, \pm 1.31$, and $-19.00 \pm 0.86 \mathrm{mV}$ in alkaline solution, respectively (Figure S2, Supporting Information). PEI and maltose polymer are cationic polyelectrolytes, and carboxylic acid is an anionic electrolyte. Because of the cationic PEI and maltose polymer, magnetic nanoparticles $\left(\mathrm{Fe}_{3} \mathrm{O}_{4}-\mathrm{PEI}, \mathrm{Fe}_{3} \mathrm{O}_{4}-\mathrm{PEI}-\mathrm{COOH}\right)$ had smaller negative potential than $\mathrm{Fe}_{3} \mathrm{O}_{4}-\mathrm{PEI}-\mathrm{COOH}$ modified with anionic carboxyl groups in alkaline condition ( $\mathrm{pH}$ 10.5).

To further confirm the functionalization of magnetic $\mathrm{Fe}_{3} \mathrm{O}_{4}$ NPs, Fourier transform infrared (FT-IR) spectrometry was performed for $\mathrm{Fe}_{3} \mathrm{O}_{4}-\mathrm{PEI}, \mathrm{Fe}_{3} \mathrm{O}_{4}-\mathrm{PEI}-\mathrm{COOH}$, and $\mathrm{Fe}_{3} \mathrm{O}_{4}-$ PEI-pMaltose NPs, respectively (Figure 2). In the spectrum of Figure $2 \mathrm{a}$, the peaks at 585 and $440 \mathrm{~cm}^{-1}$ were ascribed to the stretching vibration $\mathrm{Fe}-\mathrm{O}$ bond $\left(\mathrm{Fe}^{3+}\right.$ bond and $\mathrm{Fe}^{2+}$ bond, respectively), which was consistent with frequency bands of the spinel ferrite phase of $\mathrm{Fe}_{3} \mathrm{O}_{4}$ while the $\mathrm{Fe}-\mathrm{O}$ band for $\gamma-\mathrm{Fe}_{2} \mathrm{O}_{3}$ is usually seen at $540 \mathrm{~cm}^{-1}$. ${ }^{39}$ The broad peak centered at 3428 $\mathrm{cm}^{-1}$ was assigned to the stretching vibration of $\mathrm{N}-\mathrm{H}$ and/or $\mathrm{OH}$ bonds. The peaks at 1622 and $1557 \mathrm{~cm}^{-1}$ were attributed to the stretching vibration of the $\mathrm{C}=\mathrm{O}$ bond and deformation vibration of $\mathrm{N}-\mathrm{H}$ of amide group, respectively. Compared with the above spectrum of $\mathrm{Fe}_{3} \mathrm{O}_{4}-\mathrm{PEI}$, the new broad peak at $3448-2964 \mathrm{~cm}^{-1}$ of the carboxyl group and the enhanced peak at $1557 \mathrm{~cm}^{-1}$ of the amide group in the spectrum of $\mathrm{Fe}_{3} \mathrm{O}_{4}-$ $\mathrm{PEI}-\mathrm{COOH} \mathrm{NPs}$ (Figure 2b) revealed the successful modification of carboxyl groups on the surface of $\mathrm{Fe}_{3} \mathrm{O}_{4}-$

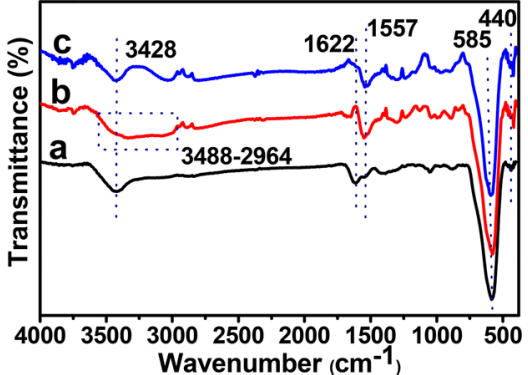

Figure 2. FT-IR spectra of $\mathrm{Fe}_{3} \mathrm{O}_{4}-\mathrm{PEI}(\mathrm{a}), \mathrm{Fe}_{3} \mathrm{O}_{4}-\mathrm{PEI}-\mathrm{COOH}$ (b) and $\mathrm{Fe}_{3} \mathrm{O}_{4}-\mathrm{PEI}-$ pMaltose (c) NPs.

PEI. Meanwhile, the disappearance of carboxyl groups (Figure $2 \mathrm{c}$ ) indicated that the maltose polymer brushes were grafted on the surface of the nanoparticles.

The magnetic hysteresis curves (Figure 3 ) indicated that the nanomaterials $\left(\mathrm{Fe}_{3} \mathrm{O}_{4}-\mathrm{PEI}, \mathrm{Fe}_{3} \mathrm{O}_{4}-\mathrm{PEI}-\mathrm{COOH}\right.$, and $\mathrm{Fe}_{3} \mathrm{O}_{4}-$

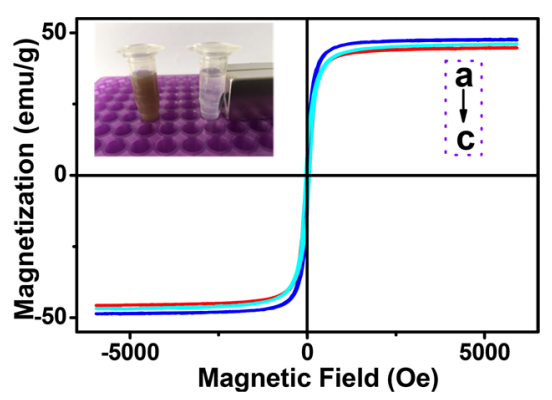

Figure 3. Magnetic hysteresis curves of $\mathrm{Fe}_{3} \mathrm{O}_{4}-\mathrm{PEI}(\mathrm{a}), \mathrm{Fe}_{3} \mathrm{O}_{4}-\mathrm{PEI}-$ $\mathrm{COOH}(\mathrm{b})$, and $\mathrm{Fe}_{3} \mathrm{O}_{4}-\mathrm{PEI}-$ pMaltose (c) NPs.

PEI-pMaltose) possessed nearly superparamagnetic properties with saturation magnetization $\left(M_{s}\right)$ of $48.25,46.53$, and 45.3 emu $\cdot \mathrm{g}^{-1}$. The $\mathrm{Fe}_{3} \mathrm{O}_{4}-\mathrm{PEI}-\mathrm{pMaltose} \mathrm{NPs}$ can be easily separated within $10 \mathrm{~s}$ with an external magnetic field (Figure 3 inset) and quickly redispersed after removal of the magnetic field.

Identification of the crystalline phases of $\mathrm{Fe}_{3} \mathrm{O}_{4}-\mathrm{PEI}$, $\mathrm{Fe}_{3} \mathrm{O}_{4}-\mathrm{PEI}-\mathrm{COOH}$ and $\mathrm{Fe}_{3} \mathrm{O}_{4}-\mathrm{PEI}-$ pMaltose NPs was performed by wide-angle X-ray diffraction (XRD) analysis (Figure S3, Supporting Information). The characteristic diffraction peaks of $\mathrm{Fe}_{3} \mathrm{O}_{4}\left(2 \theta=30.0^{\circ}, 35.4^{\circ}, 43.1^{\circ}, 53.4^{\circ}\right.$, $\left.57.0^{\circ}, 62.6^{\circ}\right)$ at the corresponding $2 \theta$ values were indexed as (220), (311), (400), (422), (511), and (440), respectively, which were in accordance with that of standard magnetite XRD pattern (JCPDS card, file No. 19-0629). Although the XRD patterns of the products clearly exhibit the spinel structure, it is difficult to distinguish the crystalline structure between $\mathrm{Fe}_{3} \mathrm{O}_{4}$ and the $\gamma$ - $\mathrm{Fe}_{2} \mathrm{O}_{3}$ phase only from the XRD patterns because of their similarity. ${ }^{40}$ The XPS technique was applied to character the magnetic products because XPS is very sensitive to $\mathrm{Fe}^{2+}$ and $\mathrm{Fe}^{3+}$ ions. The data of XPS (Figure 4a) of $\mathrm{Fe}_{3} \mathrm{O}_{4}-\mathrm{PEI}$ NPs showed a $\mathrm{C} 12$ peak around $282.7 \mathrm{eV}, \mathrm{O} 1 \mathrm{~s}$ peak at $530.6 \mathrm{eV}, \mathrm{N}$ 1 s peak at $398.5 \mathrm{eV}$, and Fe signals at about $56.6 \mathrm{eV}$ for Fe $3 \mathrm{p}$, 710.9 and $724.5 \mathrm{eV}$ for $\mathrm{Fe} 2 \mathrm{p} 3 / 2$ and $\mathrm{Fe} 2 \mathrm{p} 1 / 2$ states, respectively (Figure $4 \mathrm{~b}$ ). The absence of the satellite peaks on the magnifying pattern of $\mathrm{Fe}(2 \mathrm{p})$ also confirmed the formation of $\mathrm{Fe}_{3} \mathrm{O}_{4}$ rather than $\gamma-\mathrm{Fe}_{2} \mathrm{O}_{3}{ }^{40-42}$ which was consistent with the results from the FT-IR spectra.

The thermogravimetric analysis (TGA) curves of $\mathrm{Fe}_{3} \mathrm{O}_{4}-$ PEI, $\mathrm{Fe}_{3} \mathrm{O}_{4}-\mathrm{PEI}-\mathrm{COOH}, \mathrm{Fe}_{3} \mathrm{O}_{4}-\mathrm{PEI}-$ pMaltose NPs are 

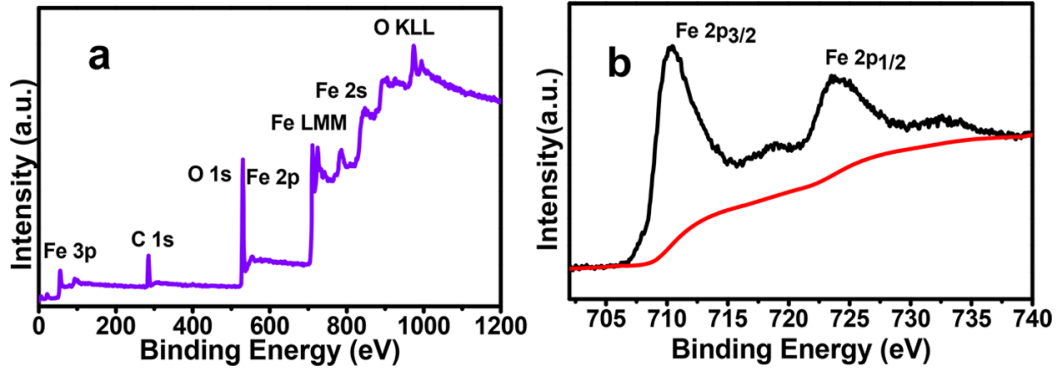

Figure 4. XPS spectrum (a) and high-resolution $\mathrm{Fe}(2 \mathrm{p})$ binding energy spectrum (b) of $\mathrm{Fe}_{3} \mathrm{O}_{4}-\mathrm{PEI}$ NPs.

shown in Figure 5. It can be seen that $4.4 \%$ weight loss occurred for $\mathrm{Fe}_{3} \mathrm{O}_{4}-$ PEI NPs (blue curve) corresponding to

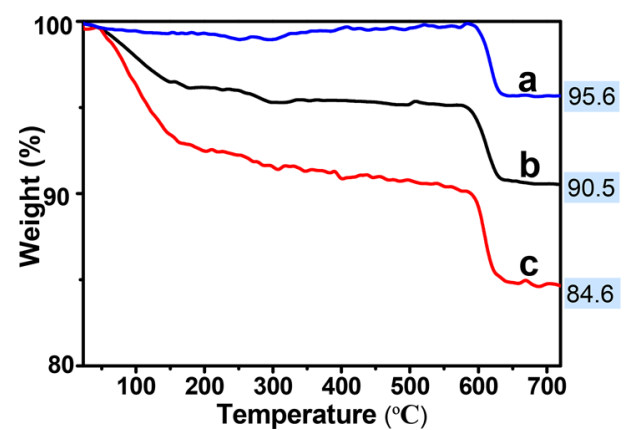

Figure 5. TGA curves of $\mathrm{Fe}_{3} \mathrm{O}_{4}-\mathrm{PEI}$ (a), $\mathrm{Fe}_{3} \mathrm{O}_{4}-\mathrm{PEI}-\mathrm{COOH}$ (b) and $\mathrm{Fe}_{3} \mathrm{O}_{4}-\mathrm{PEI}-$ pMaltose (c) NPs.

the content of PEI onto the nanoparticles surface. And there was 9.5 and $13.4 \%$ weight loss for $\mathrm{Fe}_{3} \mathrm{O}_{4}-\mathrm{PEI}-\mathrm{COOH}$, $\mathrm{Fe}_{3} \mathrm{O}_{4}$-PEI-pMaltose, respectively. From the data of TGA curves, the amount of maltose grafted onto the $\mathrm{Fe}_{3} \mathrm{O}_{4}-\mathrm{PEI}-$ pMaltose NPs was calculated to $108.2 \mu \mathrm{mol} \cdot \mathrm{g}^{-1}$.

Hydrophilicity of nanoparticles is a key evaluation factor for enrichment performance. Herein, the contact angle of prepared $\mathrm{Fe}_{3} \mathrm{O}_{4}$-PEI, $\mathrm{Fe}_{3} \mathrm{O}_{4}$-PEI-pMaltose NPs were measured with the powder tabletting method. The contact angle of $\mathrm{Fe}_{3} \mathrm{O}_{4}-$ PEI and $\mathrm{Fe}_{3} \mathrm{O}_{4}-\mathrm{PEI}-$ pMaltose NPs were $42.6^{\circ}$ and $14.7^{\circ}$, respectively (Figure 6). As expected, the angle distinctly

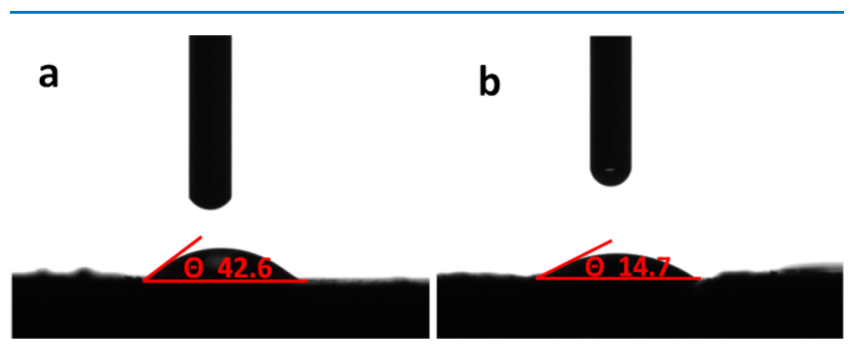

Figure 6. Water contact angle of $\mathrm{Fe}_{3} \mathrm{O}_{4}-\mathrm{PEI}$ (a) and $\mathrm{Fe}_{3} \mathrm{O}_{4}-\mathrm{PEI}-$ pMaltose (b) NPs.

decreased after modification, indicating that $\mathrm{Fe}_{3} \mathrm{O}_{4}$ NPs functionalized polymer maltose brush has superior hydrophilicity which could enhance the enrichment effect.

Glycopeptide Enrichment from Standard Proteins by $\mathrm{Fe}_{3} \mathrm{O}_{4}-\mathrm{PEI}-\mathrm{pMaltose}$ NPs. To manifest enrichment based on the hydrophilic interaction between the hydrophilicity of polymer maltose brush and targets, three synthetic nanoparticles $\left(\mathrm{Fe}_{3} \mathrm{O}_{4}-\mathrm{PEI}, \mathrm{Fe}_{3} \mathrm{O}_{4}-\mathrm{PEI}-\mathrm{COOH}, \mathrm{Fe}_{3} \mathrm{O}_{4}-\mathrm{PEI}-\right.$ pMaltose NPs) were used to enrich the glycopeptides from the standard HRP tryptic digest under the same conditions. Figure $7 \mathrm{a}$ shows the direct analysis of HRP digest (100 fmol)
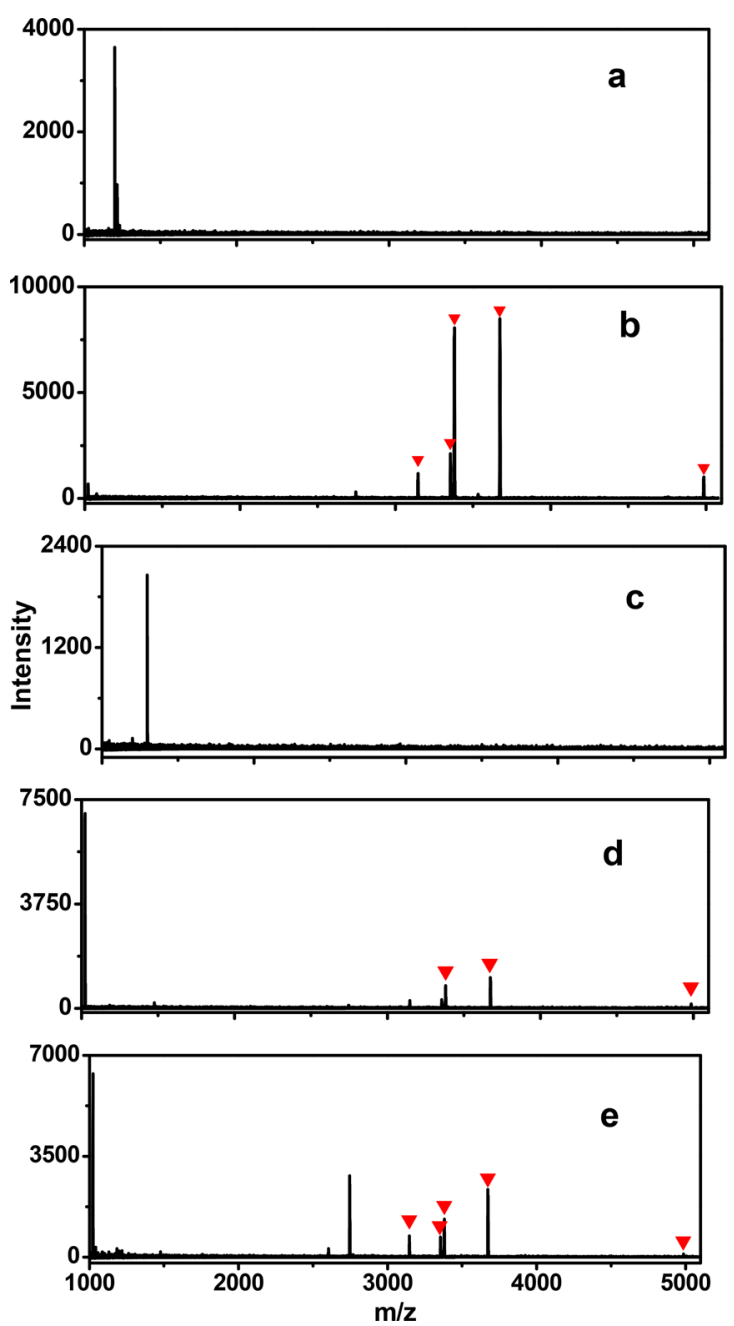

Figure 7. MALDI-TOF mass analysis of tryptic digest of HRP (100 fmol): (a) before enrichment, (b) eluent, and (c) supernatant after enrichment with $\mathrm{Fe}_{3} \mathrm{O}_{4}-\mathrm{PEI}-$ pMaltose NPs; eluent after enrichment with (d) $\mathrm{Fe}_{3} \mathrm{O}_{4}-\mathrm{PEI}$, and (e) $\mathrm{Fe}_{3} \mathrm{O}_{4}-\mathrm{PEI}-\mathrm{COOH}$ NPs. The peaks of glycopeptides are marked with a red inverted triangle.

without the enrichment procedure. The signal peaks of low abundance of glycopeptides were completely suppressed, and no target analyte was detected. After enrichment $\mathrm{Fe}_{3} \mathrm{O}_{4}-\mathrm{PEI}$, $\mathrm{Fe}_{3} \mathrm{O}_{4}-\mathrm{PEI}-\mathrm{COOH}, \mathrm{Fe}_{3} \mathrm{O}_{4}-\mathrm{PEI}-$ pMaltose NPs, and three and five glycopeptides were distinctly identified and most abundant nonglycopeptides were efficiently removed (Figure $7 \mathrm{~b}-\mathrm{e})$. Detailed information on glycopeptides enriched by 
$\mathrm{Fe}_{3} \mathrm{O}_{4}-\mathrm{PEI}-\mathrm{pMaltose}$ NPs from HRP tryptic digest is displayed in Table S1 (Supporting Information). The greater number and enhanced signal intensity of glycopeptides were observed for $\mathrm{Fe}_{3} \mathrm{O}_{4}-\mathrm{PEI}-$ pMaltose NPs in comparsion with those for $\mathrm{Fe}_{3} \mathrm{O}_{4}-\mathrm{PEI}$ and $\mathrm{Fe}_{3} \mathrm{O}_{4}-\mathrm{PEI}-\mathrm{COOH}$. After the HRP tryptic digest was adsorbed by $\mathrm{Fe}_{3} \mathrm{O}_{4}-\mathrm{PEI}-$ pMaltose NPs, no glycopeptide peaks were found in the residual solution (Figure 7c). The results demonstrated the good hydrophilicity $\mathrm{Fe}_{3} \mathrm{O}_{4}-$ PEI-pMaltose NPs has as highly specific to glycopeptides.

The detection limit of $\mathrm{Fe}_{3} \mathrm{O}_{4}-\mathrm{PEI}-$ pMaltose NPs for $\mathrm{N}$ glycopeptides enrichment was investigated with different concentrations of HRP tryptic digest. As shown in Figure 8a,

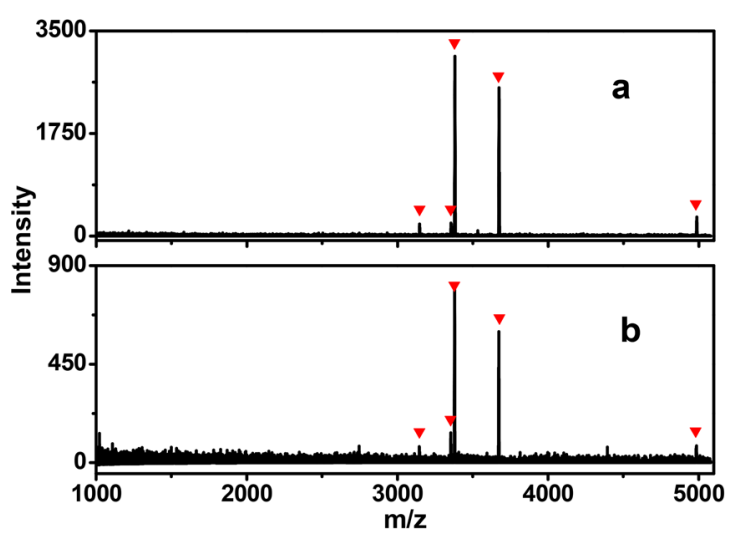

Figure 8. MALDI-TOF mass analysis of different concentrations of HRP tryptic digests: (a) 50, (b) 10 fmol HRP after enrichment with $\mathrm{Fe}_{3} \mathrm{O}_{4}-\mathrm{PEI}-$ pMaltose NPs. The peaks of glycopeptides are marked with a red inverted triangle.

five target glycopeptides with high signal intensity were identified when the concentration of HRP digests was 50 fmol. Even when the concentration of HRP digests was as low as $10 \mathrm{fmol}$, five target glycopeptides were still observed (Figure $8 b)$.

To further evaluate the enrichment selectivity of $\mathrm{Fe}_{3} \mathrm{O}_{4}-$ PEI-pMaltose NPs between nonglycopeptides and glycopeptides, the mixture of HRP and BSA tryptic digest with different mass ratios was investigated. As shown in Figure 9, seven glycopeptides were identified from tryptic BSA and HRP at ratios of $1: 1$ and 10:1 after enrichment by $\mathrm{Fe}_{3} \mathrm{O}_{4}-\mathrm{PEI}-$ pMaltose NPs. When the ratios were increased to 50:1 and 100:1, five glycopeptides and four glycopeptides were still detected, respectively, albeit with trace nonglycopeptide signals (Figure 9c,d). The results demonstrated that the $\mathrm{Fe}_{3} \mathrm{O}_{4}-\mathrm{PEI}-$ pMaltose NPs has great potential for N-glycopeptides enrichment from complex biological samples.

To demonstrated that $\mathrm{Fe}_{3} \mathrm{O}_{4}-\mathrm{PEI}-$ pMaltose NPs have no bias toward different kinds of glycans, tryptic IgG (20 pmol) which contains a different glycoform from HRP was employed. Before enrichment, merely two glycopeptides were detected with low peak intensities, and there existed a great number of interferences from nonglycopeptides (Figure 10a). Seventeen high signal-to-noise glycopeptides were obtained after enrichment by $\mathrm{Fe}_{3} \mathrm{O}_{4}-\mathrm{PEI}-$ pMaltose NPs (Figure 10b, detailed information is listed in Table S2, Supporting Information).The eluted glycopeptides were deglycosylated by PNGaseF, and two strong signals of deglycosylated peptides were detected (Figure 10c).

Evaluation of Binding Capacity of $\mathrm{Fe}_{3} \mathrm{O}_{4}-\mathrm{DA}-$ Maltose NPs for Glycopeptide. Different amounts $(5-30 \mu \mathrm{g})$ of

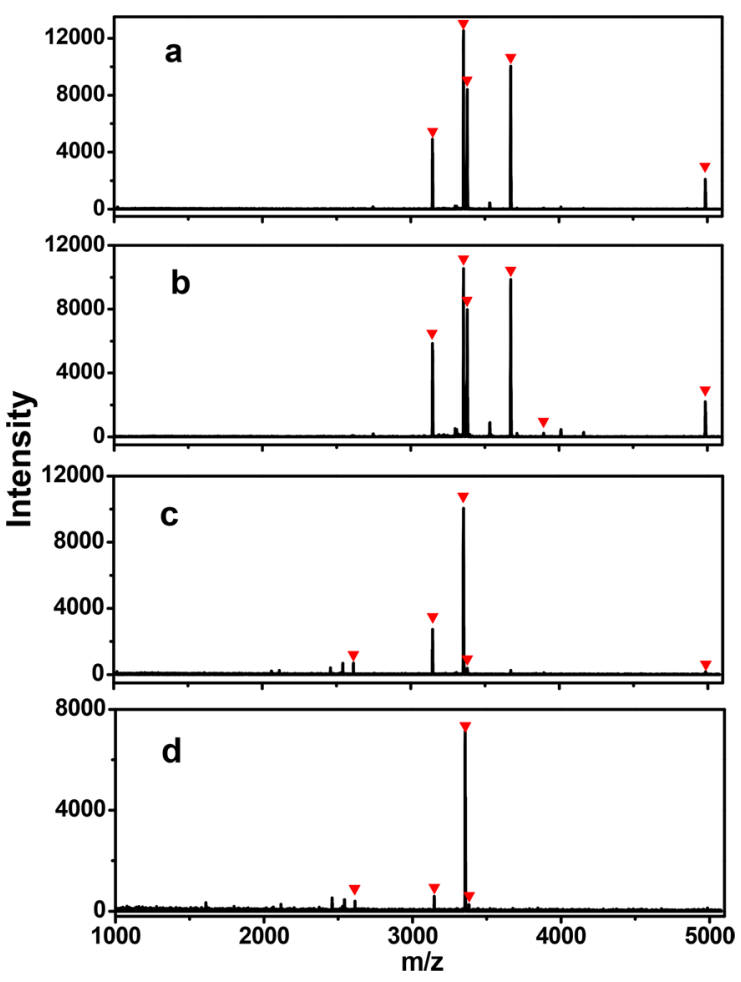

Figure 9. MALDI-TOF mass analysis of tryptic BSA and HRP after enrichment. The mass ratios of BSA/HRP are 1:1 (a), 10:1 (b), 50:1 (c), and 100:1 (d). The peaks of glycopeptides are marked with a red inverted triangle.
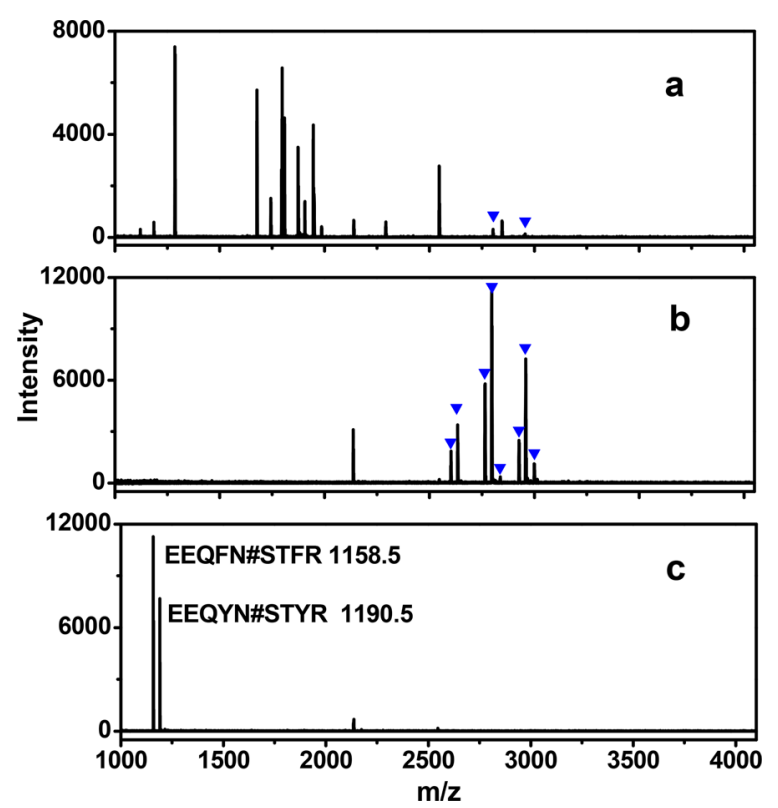

Figure 10. MALDI-TOF mass analysis of tryptic digests of IgG (20pmol): direct analysis (a), after enrichment with $\mathrm{Fe}_{3} \mathrm{O}_{4}$-PEIpMaltose NPs (b), and deglycosylation by PNGase F (c). The peaks of glycopeptides are marked with a blue inverted triangle.

$\mathrm{Fe}_{3} \mathrm{O}_{4}-\mathrm{PEI}-\mathrm{pMaltose} \mathrm{NPs}$ were used to treat $3 \mu \mathrm{g}$ of IgG digest. The elution was analyzed by MALDI-TOF MS. When the peak intensity of representative glycopeptides reached maximum, the total amount of glycopeptides were bonded onto the NPs. The binding capacity was calculated by $3 \mu \mathrm{g}$ IgG digest to NPs. As shown in Figure 11, the N-glycopeptides 


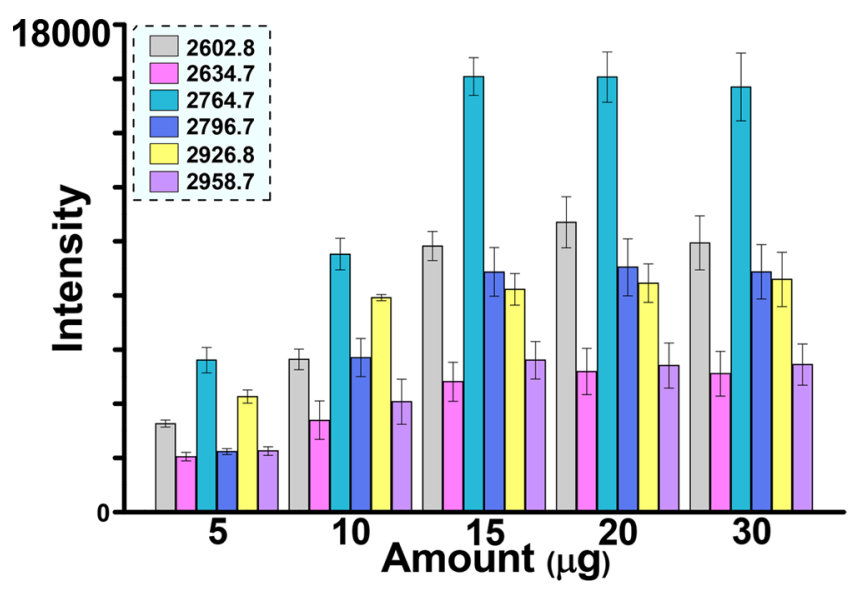

Figure 11. Intensity of six selected N-glycopeptides from tryptic digests of human $\operatorname{IgG}(3 \mu \mathrm{g})$ after enrichment by different amount of $\mathrm{Fe}_{3} \mathrm{O}_{4}-\mathrm{PEI}-$ pMaltose NPs.

from $3 \mu \mathrm{g}$ IgG digest were captured by $15 \mu \mathrm{g}$ of $\mathrm{Fe}_{3} \mathrm{O}_{4}-\mathrm{PEI}-$ pMaltose NPs, therefore the binding capacity of $\mathrm{Fe}_{3} \mathrm{O}_{4}-\mathrm{PEI}-$ pMaltose NPs for $\mathrm{N}$-glycopeptides was about $200 \mathrm{mg} \mathrm{g}^{-1}$, which greatly exceeded the binding capacity of other maltose functionalized $\mathrm{Fe}_{3} \mathrm{O}_{4}$ materials such as $\mathrm{Fe}_{3} \mathrm{O}_{4} @ \mathrm{SiO}_{2} @ P E G-$ Maltose, ${ }^{23-26} \mathrm{Fe}_{3} \mathrm{O}_{4}$-DA-Maltose, ${ }^{33}$ and $\mathrm{Fe}_{3} \mathrm{O}_{4}$-PEI-Maltose, ${ }^{34}$ NPs.

The Reusability and Stability of $\mathrm{Fe}_{3} \mathrm{O}_{4}-\mathrm{PEI}-$ pMaltose NPs. To evaluate the reusability and stability, $\mathrm{Fe}_{3} \mathrm{O}_{4}-\mathrm{PEI}-$ pMaltose NPs placed for two month at room temperature were applied to enrich standard HRP glycopeptides from tryptic digest in consecutive times. As shown in Figure S4 (Supporting Information), the N-linked glycopeptides were clearly detected in the first time and sixth time run, indicating that as-prepared $\mathrm{Fe}_{3} \mathrm{O}_{4}-\mathrm{PEI}-$ pMaltose NPs owned excellent repeatability and long-term stability for $\mathrm{N}$-linked glycopeptides enrichment.

Enrichment Recovery of Glycopeptides by $\mathrm{Fe}_{3} \mathrm{O}_{4}-$ PEl-pMaltose NPs. The stable-isotope dimethyl labeling samples were used to study the enrichment recovery of $\mathrm{Fe}_{3} \mathrm{O}_{4}-$ PEI-pMaltose NPs for glycopeptides. Briefly, the heavy-tagged tryptic digest was enriched with $\mathrm{Fe}_{3} \mathrm{O}_{4}-\mathrm{PEI}-$ pMaltose NPs, and then the eluted $\mathrm{N}$-glycopeptides were mixed up with the light-tagged tryptic digest. The mixed dimethyl labeling samples were enriched with $\mathrm{Fe}_{3} \mathrm{O}_{4}-\mathrm{PEI}-\mathrm{pMaltose} \mathrm{NPs}$, followed with elution, deglycosylation by PNGaseF, and MALDI-TOF analysis. The recovery yield $(\mathrm{H} / \mathrm{L})$ was calculated by the peak intensity ratio of heavy isotope-labeled peptides to the corresponding light isotope-labeled peptides. Meanwhile, the recovery yield $(\mathrm{L} / \mathrm{H})$ was also evaluated (Figure S5, Table S3, Supporting Information). The recovery yields $(\mathrm{L} / \mathrm{H}$ or $\mathrm{H} / \mathrm{L})$ of two deglycosylated stable-isotope dimethyl labeling peptides $(\mathrm{m} / z=1186.0,1218.0$ or $1190.1,1222.1)$ were about $89 \%$ or $85 \%$, respectively, which confirmed that $\mathrm{Fe}_{3} \mathrm{O}_{4}-\mathrm{PEI}-$ pMaltose NPs have great potential for N-glycopeptides enrichment.

Glycopeptide Enrichment from Human Renal Mesangial Cell (HRMC) Tryptic Digest by $\mathrm{Fe}_{3} \mathrm{O}_{4}-\mathrm{PEI}-$ pMaltose NPs. Human renal mesangial cells serve as a filtration barrier of the kidney. The injury of mesangial cells could cause diabetic nephropathy, leading end-stage renal disease. Emerging evidence indicates that mesangial cells can be damaged by high glucose, however the mechanism is unclear. Given such outstanding performance in standard glycopeptides enrichment, $\mathrm{Fe}_{3} \mathrm{O}_{4}-\mathrm{PEI}-\mathrm{pMaltose}$ NPs were applied to enrich glycopep- tides from human renal mesangial cell tryptic digest, treated with high glucose, and followed by LC-MS/MS analysis (cell culture, protein extraction, MS/MS data analysis, see Supporting Information). Followed by the Uniprot-Human protein sequence database for analysis, 449 N-linked glycopeptides, representing 323 different glycoproteins and 476 glycosylation sites were identified. The number of proteins and glycosylation sites detected extremely exceeded those of our previous $\mathrm{Fe}_{3} \mathrm{O}_{4}$-DA-Maltose NPs. ${ }^{33}$ Detailed information on glycan structures of human renal mesangial cells after enrichment by $\mathrm{Fe}_{3} \mathrm{O}_{4}-\mathrm{PEI}-\mathrm{pMaltose}$ NPs is listed in Table S4 (Supporting Information).

\section{CONCLUSIONS}

In summary, novel polymer maltose brushes-interspersed $\mathrm{Fe}_{3} \mathrm{O}_{4}$ magnetic nanoparticles $\left(\mathrm{Fe}_{3} \mathrm{O}_{4}-\mathrm{PEI}-\right.$ pMaltose NPs) were synthesized successfully via a facile two-step method for selective enrichment of N-glycopeptides. On the basis of its good biocompatibility, excellent hydrophilicity, and magnetic responsibility, $\mathrm{Fe}_{3} \mathrm{O}_{4}-\mathrm{PEI}-\mathrm{pMaltose}$ functionalized with a hyperbranched PEI structure and high maltose polymer chains loading exhibited distinctly improved selectivity, sensitivity, large binding capacity, and good recovery for HRP and IgG digests. A total of $449 \mathrm{~N}$-linked glycopeptides, representing 323 different glycoproteins and 476 glycosylation sites were found from human renal mesangial cell tryptic digest. It can be expected that the $\mathrm{Fe}_{3} \mathrm{O}_{4}-\mathrm{PEI}-$ pMaltose NPs would hold great potential in $\mathrm{N}$-glycoproteome research.

\section{ASSOCIATED CONTENT}

\section{Supporting Information}

The Supporting Information is available free of charge on the ACS Publications website at DOI: 10.1021/acsomega.7b01788.

Detailed procedure of cell culture and protein extraction, LC-MS/MS analysis and MS/MS data analysis; schematic illustration of maltose polymer brush with ATRP polymerization and synthesis of maltose polymer brush; hydrodynamic diameter histograms of $\mathrm{Fe}_{3} \mathrm{O}_{4}-$ PEI-pMaltose NPs; MALDI-TOF MS spectra of the isotope dimethylation labeled human IgG peptides after deglycosylation by PNGaseF; zeta potentials, XRD patterns of $\mathrm{Fe}_{3} \mathrm{O}_{4}-\mathrm{PEI}, \mathrm{Fe}_{3} \mathrm{O}_{4}-\mathrm{PEI}-\mathrm{COOH}$ and $\mathrm{Fe}_{3} \mathrm{O}_{4}-\mathrm{PEI}-\mathrm{pMaltose} \mathrm{NPs}$; the repeatability performance of the $\mathrm{Fe}_{3} \mathrm{O}_{4}-\mathrm{PEI}-\mathrm{pMaltose}$ NPs for enrichemnt of 100 fmol tryptic HRP in consecutive times; the recovery of $\mathrm{N}$-glycosylation motifs from tryptic digests of IgG enriched by $\mathrm{Fe}_{3} \mathrm{O}_{4}-\mathrm{PEI}-\mathrm{pMaltose} \mathrm{NPs}$; identified glycopeptides and glycan structures of human HRP, IgG digests and human renal mesangial cells after enrichment by $\mathrm{Fe}_{3} \mathrm{O}_{4}-\mathrm{PEI}-$ pMaltose NPs (PDF)

\section{AUTHOR INFORMATION}

\section{Corresponding Author}

*Fax: (+86) 22-2350-2458. E-mail: 1xchen@nankai.edu.cn. ORCID

Langxing Chen: 0000-0002-8616-9207

Notes

The authors declare no competing financial interest. 


\section{ACKNOWLEDGMENTS}

We gratefully appreciate the financial support by the National Natural Science Foundation of China (No 21475067), the Natural Science Foundation of Tianjin (No. 15JCYBJC20600), and the CAMS Innovation Fund for Medical Sciences (CIFMS, 2017-I2M-3-019 and 2016-I2M-3-022).

\section{REFERENCES}

(1) Roth, J.; Zuber, C.; Park, S.; Jang, I.; Lee, Y.; Kysela, K. G.; Le Fourn, V.; Santimaria, R.; Guhl, B.; Cho, J. W. Protein NGlycosylation, Protein Folding, and Protein Quality Control. Mol. Cells 2010, 30, 497-506.

(2) Demetriou, M.; Granovsky, M.; Quaggin, S.; Dennis, J. W. Negative Regulation of T-cell Activation and Autoimmunity by Mgat5 N-Glycosylation. Nature 2001, 409, 733-739.

(3) Partidge, E. A.; Roy, C. L.; Guglielmo, G. M.; Pawling, J.; Cheung, P.; Granovsky, M.; Nabi, I. R.; Wrana, J. L.; Dennis, J. W. Regulation of Cytokine Receptors by Golgi N-Glycan Processing and Endocytosis. Science 2004, 306, 120-124.

(4) Ohtsubo, K.; Marth, J. D. Glycosylation in Cellular Mechanisms of Health and Disease. Cell 2006, 5, 855-867.

(5) Nita-Lazar, M.; Noonan, V.; Rebustini, I.; Walker, J.; Menko, A. S.; Kukuruzinska, M. A. Overexpression of DPAGT1 Leads to Aberrant N-Glycosylation of E-Cadherin and Cellular Discohesion in Oral Cancer. Cancer Res. 2009, 14, 5673-5680.

(6) Dell, A.; Morris, H. R. Glycoprotein Structure Determination by Mass Spectrometry. Science 2001, 291, 2351-2356.

(7) Baycin-Hizal, D.; Tian, Y.; Akan, I.; Jacobson, E.; Clark, D.; Wu, A.; Jampol, R.; Palter, K.; Betenbaugh, M.; Zhang, H. Glycofish: A Database of Zebrafish N-linked Glycoproteins Identified Using SPEG Method Coupled with LC/MS. Anal. Chem. 2011, 83, 5296-5303.

(8) Ding, W.; Hill, J. J.; Kelly, J. Selective Enrichment of Glycopeptides from Glycoprotein Digests Using Ion-Pairing NormalPhase Liquid Chromatography. Anal. Chem. 2007, 79, 8891-8899.

(9) Dela Rosa, M. A.; Chen, W. C.; Chen, Y. J.; Obena, R. P.; Chang, C. H.; Capangpangan, R. Y.; Su, T. H.; Chen, C. L.; Chen, P. J.; Chen, Y. J. One-Pot Two-Nanoprobe Assay Uncovers Targeted Glycoprotein Biosignature. Anal. Chem. 2017, 89, 3973-3980.

(10) Kaji, H.; Yamauchi, Y.; Takahashi, N.; Isobe, T. Mass Spectrometric Identification of N-Linked Glycopeptides Using Lectin-Mediated Affinity Capture and Glycosylation Site-Specific Stable Isotope Tagging. Nat. Protoc. 2006, 6, 3019-3027.

(11) Lu, Y. W.; Chien, C. W.; Lin, P. C.; Huang, L. D.; Chen, C. Y.; Wu, S. W.; Han, C. L.; Khoo, K. H.; Lin, C. C.; Chen, Y. J. BadLectins: Boronic Acid-Decorated Lectins with Enhanced Binding Affinity for the Selective Enrichment of Glycoproteins. Anal. Chem. 2013, 85, 8268-8276.

(12) Kim, J. Y.; Kim, S. K.; Kang, D.; Moon, M. H. Dual Lectin-Based Size Sorting Strategy to Enrich Targeted N-Glycopeptides by Asymmetrical Flow Field-Flow Fractionation:Profiling Lung Cancer Biomarkers. Anal. Chem. 2012, 84, 5343-5350.

(13) Huang, J. F.; Wan, H.; Yao, Y. T.; Li, J. N.; Cheng, K.; Mao, J. W.; Chen, J.; Wang, Y.; Qin, H. Q.; Zhang, W. B.; Ye, M. L.; Zou, H. F. Highly Efficient Release of Glycopeptides from Hydrazide Beads by Hydroxylamine Assisted PNGase F Deglycosylation for N-Glycoproteome Analysis. Anal. Chem. 2015, 87, 10199-10204.

(14) Liu, L. T.; Yu, M.; Zhang, Y.; Wang, C. C.; Lu, H. J. Hydrazide Functionalized Core-Shell Magnetic Nanocomposites for Highly Specific Enrichment of N-Glycopeptides. ACS Appl. Mater. Interfaces 2014, 6, 7823-7832.

(15) Zhang, L. J.; Jiang, H. C.; Yao, J.; Wang, Y. L.; Fang, C. Y.; Yang, P. Y.; Lu, H. J. Highly Specific Enrichment of N-Linked Glycopeptides Based on Hydrazide Functionalized Soluble Nanopolymers. Chem. Commun. 2014, 50, 1027-1029.

(16) Zhang, X. H.; Wang, J. W.; He, X. W.; Chen, L. X.; Zhang, Y. K. Tailor-Made Boronic Acid Functionalized Magnetic Nanoparticles with a Tunable Polymer Shell-Assisted for the Selective Enrichment of
Glycoproteins/Glycopeptides. ACS Appl. Mater. Interfaces 2015, 7, 24576-24584.

(17) Wang, Y. L.; Liu, M. B.; Xie, L. Q.; Fang, C. Y.; Xiong, H. M.; Lu, H. J. Highly Efficient Enrichment Method for Glycopeptide Analyses: Using Specific and Nonspecific Nanoparticles Synergistically. Anal. Chem. 2014, 86, 2057-2064.

(18) Ma, R. N.; Hu, J. J.; Cai, Z. W.; Ju, H. X. Facile Synthesis of Boronic Acid-Functionalized Magnetic Carbon Nanotubes for Highly Specific Enrichment of Glycopeptides. Nanoscale 2014, 6, 3150-3156.

(19) Wang, J. X.; Wang, Y. N.; Gao, M. X.; Zhang, X. M.; Yang, P. Y. Multilayer Hydrophilic Poly(phenol-formaldehyde resin)-Coated Magnetic Graphene for Boronic Acid Immobilization as aNovel Matrix for Glycoproteome Analysis. ACS Appl. Mater. Interfaces 2015, 7, 16011-16017.

(20) Lin, Z. A.; Pang, J. L.; Yang, H. H.; Cai, Z. W.; Zhang, L.; Chen, G. N. One-Pot Synthesis of an Organic-Inorganic Hybrid Affinity Monolithic Column for Specific Capture of Glycoproteins. Chem. Commun. 2011, 47, 9675-9677.

(21) Lin, Z. A.; Wang, J.; Tan, X. Q.; Sun, L. X.; Yu, R. F.; Yang, H. H.; Chen, G. N. Preparation of Boronate-Functionalized Molecularly Imprinted Monolithic Column with Polydopamine Coating for Glycoprotein Recognition and Enrichment. J. Chromatogr. A 2013, 1319, 141-147.

(22) Yu, L.; Li, X.; Guo, Z.; Zhang, X.; Liang, X. Hydrophilic Interaction Chromatography Based Enrichment of Glycopeptides by Using Click Maltose: A Matrix with High Selectivity and Glycosylation Heterogeneity Coverage. Chem. - Eur. J. 2009, 15, 12618-12626.

(23) Xiong, Z. C.; Zhao, L.; Wang, F. J.; Zhu, J.; Qin, H. Q.; Wu, R. A.; Zhang, W. B.; Zou, H. F. Synthesis of Branched PEG Brushes Hybrid Hydrophilic Magnetic Nanoparticles for the Selective Enrichment of N-linked Glycopeptides. Chem. Commun. 2012, 48, 81388140.

(24) Chen, R.; Seebun, D.; Ye, M. L.; Zou, H. F.; Figeys, D. SiteSpecific Characterization of Cell Membrane N-Glycosylation with Integrated Hydrophilic Interaction Chromatography Solid Phase Extraction and LC-MS/MS. J. Proteomics 2014, 103, 194-203.

(25) Selman, M. H. J.; Hemayatkar, M.; Deelder, A. M.; Wuhrer, M. Cotton HILIC SPE Microtips for Microscale Purification and Enrichment of Glycans and Glycopeptides. Anal. Chem. 2011, 83, 2492-2499.

(26) Ma, W.; Xu, L. N.; Li, Z.; Sun, Y. L.; Bai, Y.; Liu, H. W. PostSynthetic Modification of an Amino-Functionalized Metal-Organic Framework for Highly Efficient Enrichment of N-Linked Glycopeptides. Nanoscale 2016, 8, 10908-10912.

(27) Jin, T.; Xiong, Z. C.; Zhu, X.; Mehio, N.; Chen, Y. J.; Hu, J.; Zhang, W. B.; Zou, H. F.; Liu, H. L.; Dai, S. Template-Free Synthesis of Mesoporous Polymers for Highly Selective Enrichment of Glycopeptides. ACS Macro Lett. 2015, 5, 570-574.

(28) Wan, H.; Huang, J. F.; Liu, Z. S.; Li, J. N.; Zhang, W. B.; Zou, H. F. A Dendrimer-Assisted Magnetic Graphene-Silica Hydrophilic Composite for Efficient and Selective Enrichment of Glycopeptides from the Complex Sample. Chem. Commun. 2015, 51, 9391-9394.

(29) Ma, W.; Xu, L. N.; Li, X. J.; Shen, S. S.; Wu, M.; Bai, Y.; Liu, H. W. Cysteine-Functionalized Metal-Organic Framework: Facile Synthesis and High Efficient Enrichment of $\mathrm{N}$-linked Glycopeptides in Cell Lysate. ACS Appl. Mater. Interfaces 2017, 9, 19562-19568.

(30) Sun, N. R.; Wang, J. W.; Yao, J. Z.; Deng, C. H. Hydrophilic Mesoporous Silica Materials for Highly Specific Enrichment of NLinked Glycopeptide. Anal. Chem. 2017, 89, 1764-1771.

(31) Jiang, B.; Liang, Y.; Wu, Q.; Jiang, H.; Yang, K. G.; Zhang, L. H.; Liang, Z.; Peng, X. J.; Zhang, Y. K. New GO-PEI-Au-L-Cys ZICHILIC Composites: Synthesis and Selective Enrichment of Glycopeptides. Nanoscale 2014, 6, 5616-5619.

(32) Li, J. N.; Wang, F. J.; Liu, J.; Xiong, Z. C.; Huang, G.; Wan, H.; Liu, Z. Y.; Cheng, K.; Zou, H. F. Functionalizing with glycopeptide dendrimers significantly enhances the hydrophilicity of the magnetic nanoparticles. Chem. Commun. 2015, 51, 4093-4096.

(33) Bi, C. F.; Zhao, Y. R.; Shen, L. J.; Zhang, K.; He, X. W.; Chen, L. X.; Zhang, Y. K. Click Synthesis of Hydrophilic Maltose-Function- 
alized Iron Oxide Magnetic Nanoparticles Based on Dopamine Anchors for Highly Selective Enrichment of Glycopeptides. ACS Appl. Mater. Interfaces 2015, 7, 24670-24678.

(34) Li, J. N.; Wang, F. J.; Wan, H. J.; Liu, J.; Liu, Z. Y.; Cheng, K.; Zou, H. F. Magnetic Nanoparticles Coated with Maltose-Functionalized Polyethyleneimine for Highly Efficient Enrichment of NGlycopeptides. J. Chromatogr. A 2015, 1425, 213-220.

(35) Yeh, C. H.; Chen, S. H.; Li, D. T.; Lin, H. P.; Huang, H. J.; Chang, C. I.; Shih, W. L.; Chern, C. L.; Shi, F. K.; Hsu, J. L. Magnetic Bead-Based Hydrophilic Interaction Liquid Chromatography of Glycopeptide Enrichments. J. Chromatogr. A 2012, 1224, 70-78.

(36) Li, Y.; Zhang, X. M.; Deng, C. H. Functionalized Magnetic Nanoparticles for Sample Preparation in Proteomics and Peptidomics Analysis. Chem. Soc. Rev. 2013, 21, 8517-8539.

(37) Lin, Z. A.; Zheng, J. N.; Lin, F.; Zhang, L.; Cai, Z. W.; Chen, G. $\mathrm{N}$. Synthesis of Magnetic Nanoparticles with Immobilized Aminophenylboronic Acid for Selective Capture of Glycoproteins. J. Mater. Chem. 2011, 21, 518-524.

(38) Gao, C. H.; Lin, G.; Lei, Z. X.; Zheng, Q.; Lin, J. S.; Lin, Z. A. Facile Synthesis of Core-Shell Structured Magnetic Covalent Organic Framework Composite Nanospheres for Selective Enrichment of Peptides with Simultaneous Exclusion of Proteins. J. Mater. Chem. B 2017, 5, 7496-7503.

(39) Mohapatra, J.; Mitra, A.; Bahadur, D.; Aslam, M. Surface Controlled Synthesis of $\mathrm{MFe}_{2} \mathrm{O}_{4}(\mathrm{M}=\mathrm{Mn}, \mathrm{Fe}, \mathrm{Co}, \mathrm{Ni}$ and $\mathrm{Zn})$ Nanoparticles and Their Magnetic Characteristics. CrystEngComm 2013, 15, 524-532.

(40) Lu, J.; Jiao, X. L.; Chen, D. R.; Li, W. Solvothermal Synthesis and Characterization of $\mathrm{Fe}_{3} \mathrm{O}_{4}$ and $\gamma$ - $\mathrm{Fe}_{2} \mathrm{O}_{3}$ Nanoplates. J. Phys. Chem. C 2009, 113, 4012-4017.

(41) Luo, J. S.; Liu, J. L.; Zeng, Z. Y.; Ng, C. F.; Ma, L. J.; Zhang, H.; Lin, J. Y.; Shen, Z. X.; Fan, H. J. Three-Dimensional Graphene Foam Supported $\mathrm{Fe}_{3} \mathrm{O}_{4}$ Lithium Battery Anodes with Long Cycle Life and High Rate Capability. Nano Lett. 2013, 13, 6136-6143.

(42) Zhang, M.; Chen, L. F.; Zheng, J.; Li, W. Z.; Hayat, T.; Alharbi, N. S.; Gan, W. J.; Xu, J. L. The Fabrication and Application of Magnetite Coated N-Doped Carbon Microtubes Hybrid Nanomaterials with Sandwich Structures. Dalton Trans. 2017, 46, 9172-9179. 